\title{
CHARACTERIZATION OF CARBON BRUSH FROM COCONUT SHELL FOR RAILWAY APPLICATION
}

\author{
M.H.I. Ibrahim ${ }^{1,2, a^{*}, \text { M.N. Said }}{ }^{2, b}$, R. Asmawi ${ }^{2, c}$ \\ ${ }^{1}$ Advanced Manufacturing \& Material Centre(AMMC), Office for Research, Innovation, \\ Commercialization \& Consultancy Management, Universiti Tun Hussein Onn Malaysia (UTHM), \\ Batu Pahat, Malaysia \\ ${ }^{2}$ Faculty of Mechanical \& Manufacturing Engineering, Universiti Tun Hussein Onn Malaysia \\ (UTHM), Batu Pahat, Malaysia

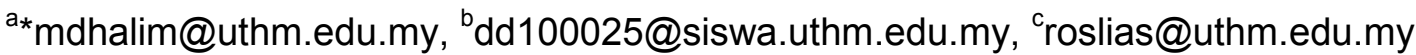

Keywords: Carbon brush, coconut shell, carbon pre-cursor.

\begin{abstract}
Carbon brush has been developed for several decades for electric machines in microelectronic era. It is the electromechanical that connect the circuit to generate an electric motor. Mineral graphite always used as a raw material in producing carbon brush beside the uses of charcoal. This study is propose to use a coconut shell (CS) as waste material that can be recycle and sustainable to produce a carbon pre-cursor. This research is conducted to minimize the percentage of graphite or charcoal as a raw material in producing a carbon brush by replaced a CS as a raw material and produce a carbon brush for railway application. Several process such as baking, crushing, sieving, mixing, compacting and sintering are used in this study to produce a carbon brush. The formation of the carbon $(\mathrm{C})$ had been produced by reaction of combustion in nitrogen atmosphere with $800^{\circ} \mathrm{C}$ temperature to produce carbon pre-cursor. The carbon brush sample then been prepared by mixing a copper powder and epoxy resin with different ratio of mixture. The suitable percentage of epoxy resin that could form a solid cylindrical shape was $15 \%$. Sample of carbon brush had been baked at $800^{\circ} \mathrm{C}$ to form the highest carbon. In this study, copper powder can produce a better conductivity where the sample can permit current flow through it. By using $60 \%$ copper powder, the sample produce less porosity which resulted for high density. Lesser the pores of carbon brush sample produce low resistivity and high conductivity.
\end{abstract}

\section{Introduction}

Carbon brushes were name from bundles of tiny copper wires, which were used as elastic contacts in the electrical engineering industry. The term of carbon brush appeared with the change to materials out of graphite and carbon. Carbon brush is the electromechanical that connect the circuit and to generate an electric motor. It is a conductive device that connect between the stationary parts that moving parts to provide an electric current. A carbon brush performs both an electrical and mechanical function within a system as a conductor of current in an electrical circuit and it is subjected to mechanical forces as it make physicals contact with a surface motion (1). This electrical contact element or carbon brush are basically used in three conditions which are in household application that run on alternative current $(\mathrm{AC})$, automotive application that run on direct current (DC) and industrial application which run on both AC and DC.

Carbon brush compounded under heat and pressure are work as a contact brushes in industry of electric. These electrical contact elements are generally compounded by mixing finely divided solid forms of carbon with a binder and subjecting the mixture to heat and pressure to compare the material. The molded plates are then heat treated to decompose the carbon compound and convert the carbon residue into a strong graphitized block having commutating properties (2).

This research propose to use a waste material (Coconut Shell) that can be recycle and sustainable to produce a carbon pre-cursor. The carbon pre-cursor is use based on waste material which will through several process such as baking, crushing, sieving, mixing, compacting and 
sintering. After carbon brush has been form, it will characterized by several testing. Minimize the use of graphite as a raw material to produce carbon brush is a main purpose by replaced it with coconut shell as a raw material for railway application.

\section{Fabrication of Sample}

There are several steps or procedure that used in this study to produce a carbon brush sample from the coconut shell starts from baking, crushing, sieving, mixing, compacting, sintering(3-5). Baking is a process that uses to heat the material (Coconut Shell). The Coconut Shell is firstly cleaned and dried into Klin furnace at temperature of $110^{\circ} \mathrm{C}$ and heated to a temperature of $350^{\circ} \mathrm{C}$ for four hour. Coconut Shell then will be changed to ash and in black color. Then, crushing process was conducted using turbular shaker mixer to produce fine particle size of carbon powder(6). In this research, crushing process run for 1 hour and speed at 6000 r.p.m with the filter size $0.08 \mathrm{~mm}$. The crushing powders are then sieved using a siever with various diameter of hole. The parameter that had been set was about 20 minutes with the amplitude was 3 amps while the smallest size of strainer was 50 $\mu \mathrm{m}$. Sieve of $140 \mu \mathrm{m}, 90 \mu \mathrm{m}$, and $45 \mu \mathrm{m}$ were used. Sieving was done for about 10 minutes. Process then proceeds by mixing process. Parameter for dry mixing are $35 \%$ of carbon $(35 \mathrm{~g}), 50 \%$ of copper $(50 \mathrm{~g})$, and $15 \%$ of epoxy resin $(15 \mathrm{~g})$ is weighing for first 10 samples. The 10 second sample parameters are $50 \%$ of carbon $(50 \mathrm{~g}), 35 \%$ of copper $(35 \mathrm{~g})$, and $15 \%$ of epoxy resin $(15 \mathrm{~g})$. By using tubular shaker mixer (3D rotation machines), the mixture is mixing within 1 hour with $300 \mathrm{rpm}$. About $100 \mathrm{~g}$ mixture was produced in every mixing process. After that, cold compaction process was done using Carver Hydraulic Press Machine at room temperature. The dimension of the sample is $1.3 \mathrm{~cm}$ diameter and $1 \mathrm{~cm}$ height. The mass of powder is 2.72 gram while the pressures that are applied to the mold are 6 tons for 5 minute. The sample produce called green body. The green body then was sintered at temperature of $800^{\circ} \mathrm{C}$ with the flow rate of $0.51 / \mathrm{min}$.

\section{Metallographic sample preparation}

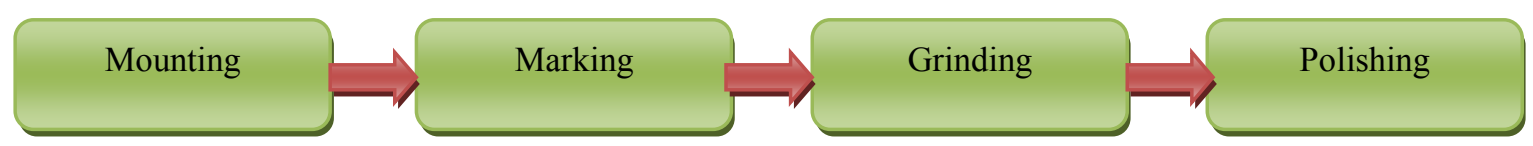

\section{Characterization and testing the sample}

The characterization and testing the sample will run on four type of characteristic which are in the properties of electrical (current), microstructure (Optical Microscope), mineralogy (X-ray Diffraction), mechanical (Hardness) and physical Properties (Density and Porosity).

\section{Result and Discussion}

From XRD testing, we can see that the peak of the pattern was representing an element of copper $(\mathrm{Cu})$. At $60 \%$ of copper, the intensity was high compared with $50 \%$ of copper. From the Figure 1 , the intensity was high at angle of 39 followed by 61.6 and 75 .

For resistivity and conductivity from Figure 2, it shows that the result of resistivity and conductivity for both percentage. When $50 \% \mathrm{Cu}$ has been used, the value of resistivity was higher than using $60 \%$ of $\mathrm{Cu}$. Cracking at the sample will contribute to resistance. This crack will resist the current to flow through it.

Resistivity value effected the value of conductivity where the lower the value of the resistivity, the highest value of conductivity. As conclusion, by using more composition of copper powder will obtain a better conductivity. This has been proved that copper has a better electrical conductivity (5). 
Figure 3(a) shows that samples B with $60 \%$ of $\mathrm{Cu}$ is more denser compared with $50 \% \mathrm{Cu}$ in sample A. For the result of porosity in Figure 3(b), sample A with $50 \% \mathrm{Cu}$ gain more porosity compared to $60 \%$ of $\mathrm{Cu}$. It is shown that larger amount of $\mathrm{Cu}$ will lowering the percentage of porosity and hence results on higher density.

Figure 4 shows the image of the sample after the carbon pre-cursor has been mixed with epoxy and with different percentage of copper powder. Generally, microstructure can be seen clearly that there were cracks on the sample surface where it means that there was a porosity at the sample. These might be occurred because of the large particle size.
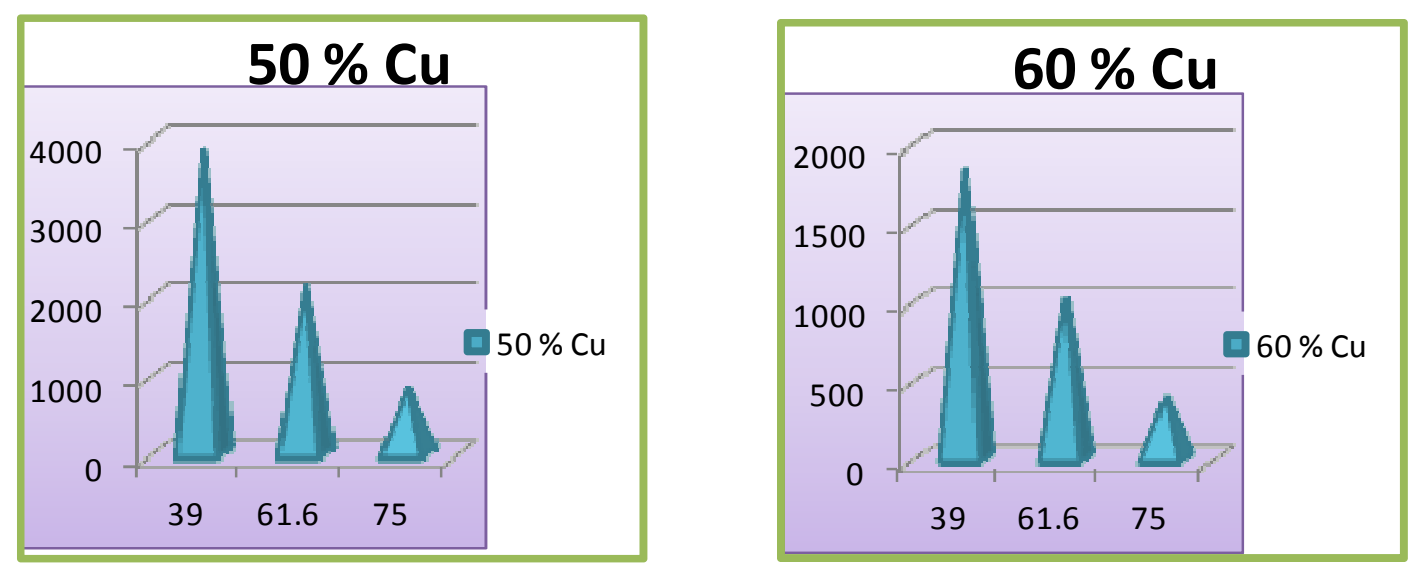

Figure 1: Graph analysis of XRD testing

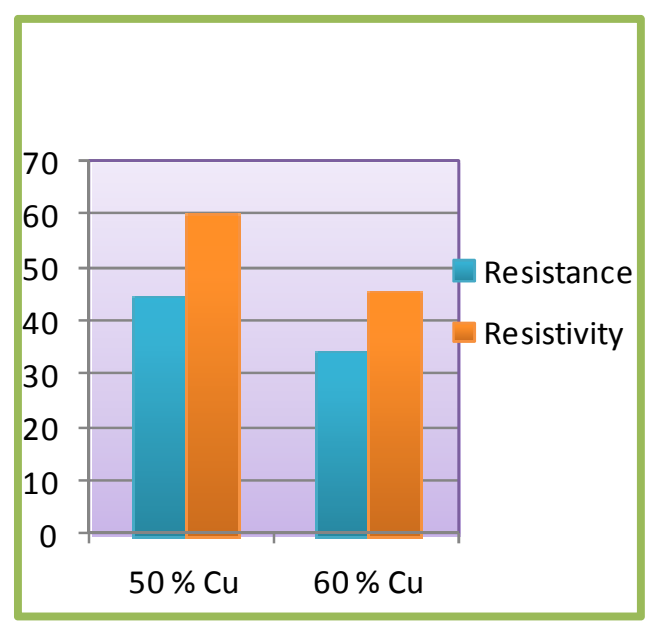

(a)

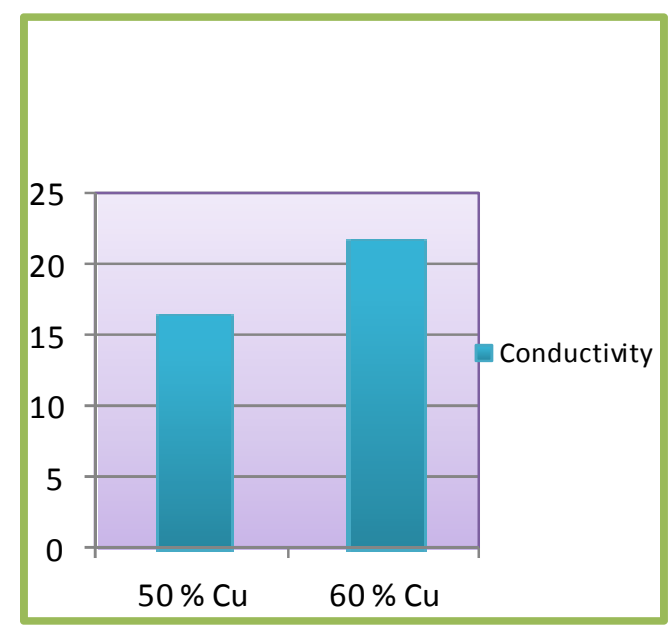

(b)

Figure 2: Graph of (a) Resistance and Resistivity ; (b) Conductivity 


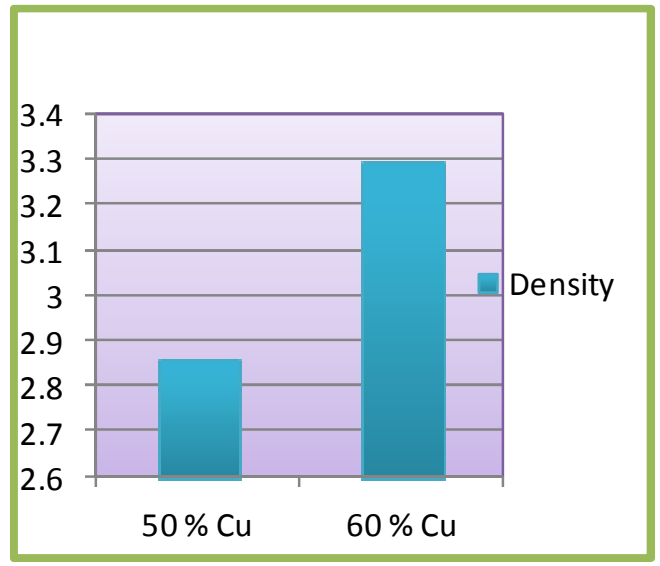

(a)

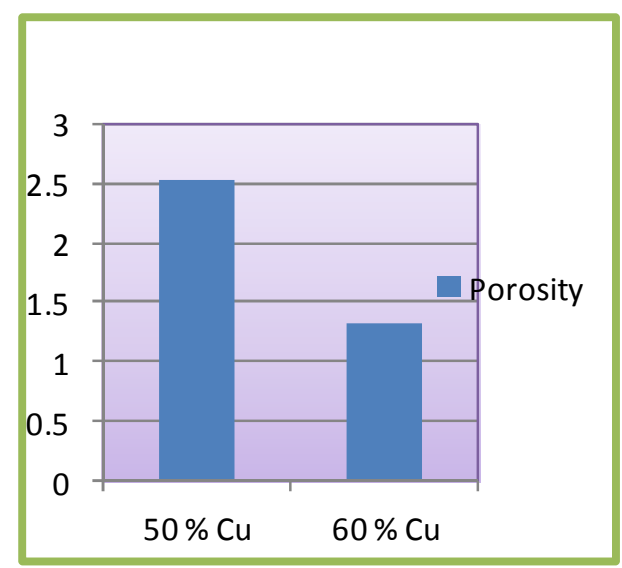

(b)

Figure 3 : Graph of (a) Density ; (b) Porosity

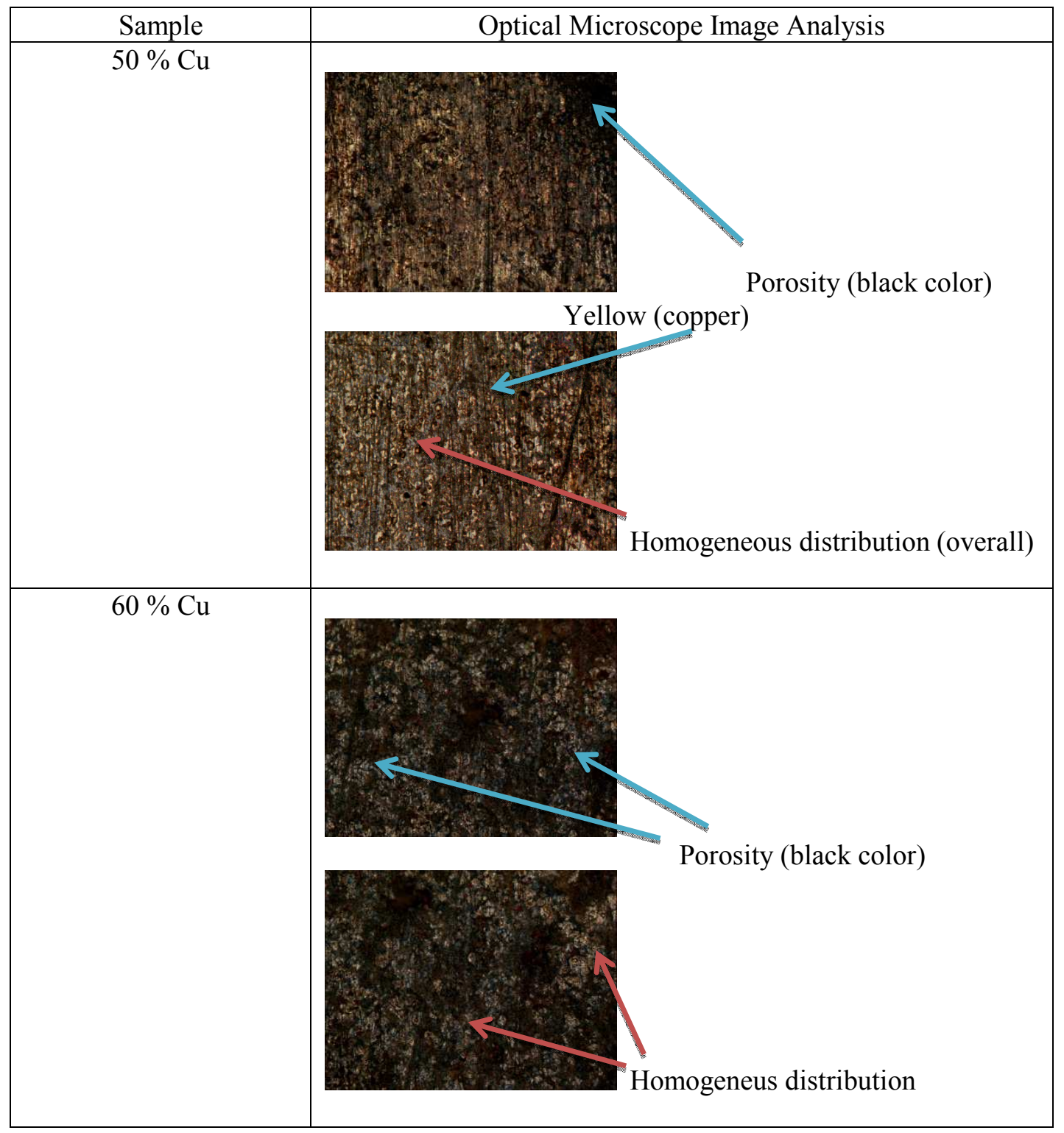

Figure 4: Microstructure Image Analysis 


\section{Conclusion}

As conclusion, carbon brush samples were successfully prepared from coconut shell as a raw material. The formation of carbon (C) has been produced by reaction of combustion in Nitrogen atmosphere with a variety of temperature to produced carbon pre-cursor. The carbon brush samples then were prepared by mixing copper powder and phenolic with different ratio of mixtures. The suitable percentages of phenolic that could form a solid cylindrical shape were $15 \%$. From the result from OM micrograph data, all samples show cracking on the surface and the color seem alike (black color). For mineralogy data, only $\mathrm{Cu}$ element had been detected in order to measure the intensity. This result may be occurred because of the carbon itself was in amorphous phase. By using more composition of copper powder, it can produce better conductivity which point out that this sample can permit current flow through it. Unfortunately, the appropriate percentages should be find out in the future to match the specification for railway application. While for density and porosity testing, the lesser the pores will results in higher density and better conductivity.

\section{Acknowledgements}

The authors would like to thank the Ministry of Higher Education Malaysia and Universiti Tun Hussein Onn Malaysia for their support and assistance with this project and for their appreciation of the benefits to be gained from independent research.

\section{Reference}

[1] Koenitzer, J. D. "Carbon Brushes for Elevator: Composition, Function and Solutions. Carbon Brush for Elevator: Composition, Function and Solutions" (2003), 1, 19.

[2] Elsey, H. M. "Carbon Brush and Method of Making" (2008) 2224, 724.

[3] Kristen, K. M. "Carbon Brush \& the Periodic Table" (2012)

[4] Kohlenstofftechnik, S., "Manufacturing Process and Material Properties of Carbon and Graphite Materials", Schunk Kohlenstofftechnik (2004).

[5] Campbell, F. "Element of Metallurgy and engineering Alloys". ASM international (2008)

[6] M.H.I. Ibrahim, M.I. Razak, M.A. Selamat, R. Asmawi, Study of Carbon-Copper (C-Cu) Composites using Local Carbon Material through Warm Compaction Process for Potential Electrical and Electronic Applications", Advanced Material Research (2014) 